\title{
Analysis of the rock stratum in a mining area in China with virtual reality technology
}

\section{Zhigang Yang}

Teaching Assistant, School of Civil Engineering and Transportation Engineering, Yellow River Conservancy Technical Institute, Kaifeng, China (corresponding author: zgyangzhig@yeah.net) (Orcid:0000-0003-3468-6488)
Yongqiang Wang

Teaching Assistant, School of Civil Engineering and Transportation

Engineering, Yellow River Conservancy Technical Institute, Kaifeng, China (Orcid:0000-0001-8392-2972)

Virtual reality (VR) technology can promote the development of mining activities. A mining area in Henan, China, was taken as an example, and a VR system of the mining area was established through the VR-Platform software. Mechanical data of the rock stratum in the mining area were analysed with a rock-fracture-process analysis system. The fracture of the mine roadway was taken as an example to analyse the rock stratum fracture of a circular roadway, a rectangular roadway and the roadway support. It was found that roadways with different shapes had different fracture situations. The cracks occurred randomly, and a closed or non-closed near-annular fracture zone might appear. The roadway support could effectively reduce the fracture of the rock stratum and improve the stability of the roadway. This study proved the important value of VR technology in the mineral industry, which is conducive to providing a scientific guidance for the planning of the mining of the mining area and promoting the orderly development of mining work.

\section{Notation}

$a_{0}$

mechanical parameter of rock

average value of the mechanical properties of primitive to element

$E_{0} \quad$ elastic modulus under undamaged conditions

$f(a) \quad$ statistical distribution density

$m$ shape parameter

$S \quad$ damage variable

$S=0 \quad$ undamaged condition

$\delta \quad$ residual strength

$\varepsilon \quad$ tensile strain

$\bar{\varepsilon} \quad$ equivalent strain

$\varepsilon_{0} \quad$ initial damage threshold

$\varepsilon_{m} \quad$ ultimate tensile strain coefficient

$\rho$ density

$\sigma_{j} \quad$ radial normal stress

$\sigma_{q} \quad$ tangential normal stress

\section{Introduction}

How to realise the safe mining of a mining area and obtain accurate geological data is a difficult and important problem which extensively concerns engineers. With the progress of computer technology, the emergence of virtual reality (VR) technology has brought a turning point to the solution of the problem. Through VR technology, engineers can intuitively understand the problems that may occur in engineering and evaluate the safety and stability of geological bodies in the mining process by simulation calculation, to make correct decisions.

VR technology has been well applied in the mining industry. Concerned with the high accident rate in coal mining, Li and Kang (2014) designed a safety training system by VR technology to provide interactive training conditions for self-rescue and escape in accidents. It was found that the effectiveness of training could be effectively improved through the VR system and the safety requirements of coal mining could be met. Xie et al. (2018) simulated coal mining through the three-dimensional (3D) simulator FMUnitySim; analysed the speed, distance and load of coal mining and conveying under different factors through the system; and then searched for the best parameter combination according to the simulation results, which provided an effective theoretical basis for safe and automatic coal mining. Zhang (2017) studied VR training technology, designed a VR training system based on helmetmounted displays and studied ten trainees. The results showed that the system could provide better user experience and use experience and play an important role in mining safety training. Bellanca et al. (2017) studied the danger search and identification of miners and searched a dangerous area after collecting data of the mining area by VR technology and creating a panoramic image of the mining area. Qi et al. (2015) studied the collision detection of coal mining in a virtual display system, compiled a collision-detection algorithm with the software development kit of the Quest3D software and proved the validity of the method through experiments. An and Cai (2010) studied the 3D geometric modelling of roadways and established 3D model tunnels through road centreline modelling, roadway section modelling and roadway intersection modelling to realise the virtual display of roadways. Wu et al. (2009) studied rock-fragmentation simulation in a virtual environment, simulated rock fragmentation through VR and geometric modelling and introduced rock fragmentation in a cone crusher to evaluate the system.

At present, the application of VR technology in the mining industry mainly includes optimisation design of mine roadways, optimisation of the blasting effect, safety training of miners, analysis of mine accidents and so on. However, there are few studies on the phenomenon of rock stratum rupture, and mechanical data of rock strata are mostly analysed by field observation or laboratory experiments. In the data analysis of mining engineering, different 
factors of rock mass are constantly changing and evolving, the changes in geological conditions are complex and the engineering data volume is large. Traditional two-dimensional data cannot help people understand the time-varying process, time-space correspondence relationship and changes and distribution rules of data, and it is difficult to prevent mining disasters effectively.

Displaying complex information through VR technology is beneficial to the comprehensive and efficient study of the failure mechanism of strata in mining areas, which is flexible and repeatable. Therefore, this study analysed mechanical data of rock strata in a mining area based on VR technology; established a virtual display system taking a mining area in Henan Province, China, as an example; and simulated the fracture condition of roadway rock strata to understand some fracture rules of rock strata. This work provides some theoretical bases for the safe mining of the mining area and is also conducive to the further application of VR technology in the mineral industry.

\section{VR technology}

VR is a comprehensive technology which combines computer, artificial intelligence, multimedia and other technologies (Wei et al., 2014). It is a new means of human-computer interaction. VR technology takes the computer as the core and combines it with other technologies to create a $3 \mathrm{D}$ virtual environment. Participants interact with objects in the virtual environment through equipment, which makes participants feel immersed in the environment. VR technology has attracted the wide attention of researchers because of its unique charm (Bastug et al., 2017).

VR converts real objects in reality into digital information and then builds a 3D model to display on the virtual platform, which can stimulate many human senses and imitate the real world to the greatest extent. It was first used in cutting-edge fields such as aerospace (Wen et al., 2014) and the military. Later, with the development of the technology, it has been widely used in education (Merchant et al., 2014), architecture, medicine (Rizzo et al., 2014) and other industries. It also has good application results in the mining industry (Stothard et al., 2015). Taking a mining area in Henan Province as an example, the mining of the mining area was studied by using VR 3D technology.

\section{Establishment of the VR system in the mining area}

\section{Establishment of the 3D model}

Three-dimensional models are the basis of a VR, which can an scientifically express the spatial correspondence of different pieces of geological information. In this study, the 3DMine software was used to build the entity model of mining area A, including surface model and underground model. Buildings and roads were generated on the basis of the surface topographic map of the mining area. Then, based on the longitude and latitude network, various underground mining areas, transportation roadways and slope lanes were established. The ore body model was established by exploratory line profiles. Some models are shown in Figures 1 and 2.

\section{Establishment of the VR system}

The hardware system used in the building of a VR system included an active stereo projector, an infrared stereo transmitter, stereo glasses and so on. The main software was VR-Platform. The construction process of the system is shown in Figure 3.

First, the 3D model of the mining area was established (e.g. see the section headed 'Establishment of the 3D model'). Then, the model was imported into the VR-Platform software. The database was

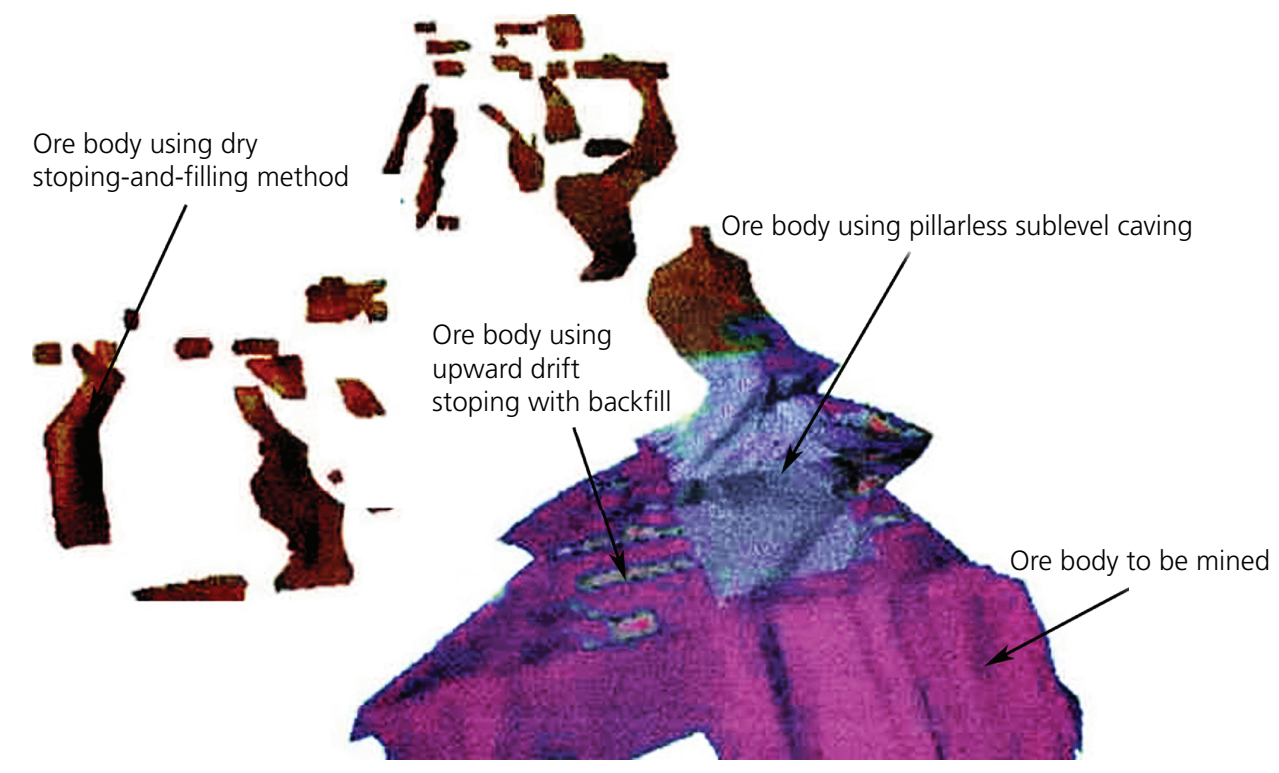

Figure 1. Ore body model 
Analysis of the rock stratum in a mining

area in China with virtual reality

technology

Yang and Wang

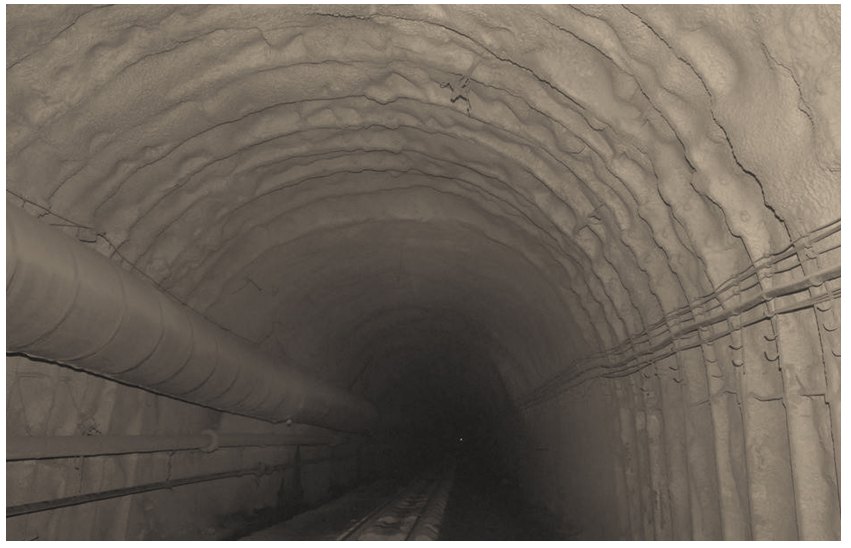

Figure 2. Internal view of roadways

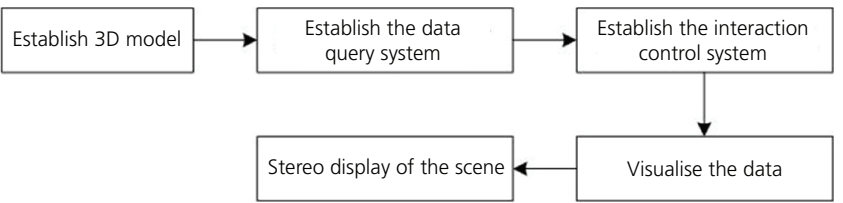

Figure 3. Building process of the VR system

established through the data collected on the spot, corresponding to the 3D model, and a query system was formed. The model of the mining area was controlled by mouse and keyboard to realise human-computer interaction. Then, the data were integrated and visualised by the software, and the whole mining area scene was displayed by the software, which is convenient for the subsequent study of mechanical data of rock strata.

\section{Calculation of the mechanics data of the rock stratum}

Through the VR system, the mining area could be comprehensively understood. The problems that might occur in the mining process could be analysed by simulation mining. The roadway rupture phenomenon is common in mining areas, which may occur in mechanised excavation and blasting excavation. Due to the heterogeneity of rock and randomness of damages, the study of the rupture phenomenon mechanism and rules and largescale experiments are difficult to carry out. Under such a situation, the good visual effect of VR can help researchers understand the crack occurrence mechanism and growth, which can provide a reliable basis for roadway support. Therefore, taking the roadway rupture as an example, a 3D model was established through VR technology to analyse mechanical data of rock strata. Data calculation was carried out in a rock-fractureprocess analysis (RFPA) system.

Suppose that the mechanical properties of rock stratum satisfied a Weibull distribution, which was expressed as
1. $f(a)=\frac{m}{a_{0}}\left(\frac{a}{a_{0}}\right)^{m-1} \mathrm{e}^{-\left(a / a_{0}\right)^{m}}$

where $m$ is the shape parameter; $a$ is the mechanical parameter of rock; $a_{0}$ is the average value of the mechanical properties of primitive to element; and $f(a)$ is the statistical distribution density.

The elastic damage model of rock was expressed as

2. $\quad S= \begin{cases}0 & \left(\varepsilon>\varepsilon_{0}\right) \\ 1-\frac{\delta}{\varepsilon E_{0}} & \left(\varepsilon_{0} \geq \varepsilon \geq \varepsilon_{m}\right) \\ 1 & \left(\varepsilon \leq \varepsilon_{m}\right)\end{cases}$

where $S$ stands for the damage variable; $S=0$ stands for the undamaged condition; $\delta$ stands for residual strength; $\varepsilon$ stands for tensile strain; $\varepsilon_{0}$ stands for the initial damage threshold; $\varepsilon_{m}$ stands for the ultimate tensile strain coefficient' and $E_{0}$ stands for the elastic modulus under undamaged conditions. Under 3D conditions, $\varepsilon$ could be replaced by the equivalent strain $\bar{\varepsilon}-$ that is

$$
S= \begin{cases}0 & \left(\bar{\varepsilon}>\varepsilon_{0}\right) \\ 1-\frac{\delta}{\bar{\varepsilon} E_{0}} & \left(\varepsilon_{0} \geq \bar{\varepsilon} \geq \varepsilon_{m}\right) \\ 1 & \left(\bar{\varepsilon} \leq \varepsilon_{m}\right)\end{cases}
$$

Suppose that the model of the rock stratum of the roadway was as shown in Figure 4; the radius of circle was $a$, the side length of

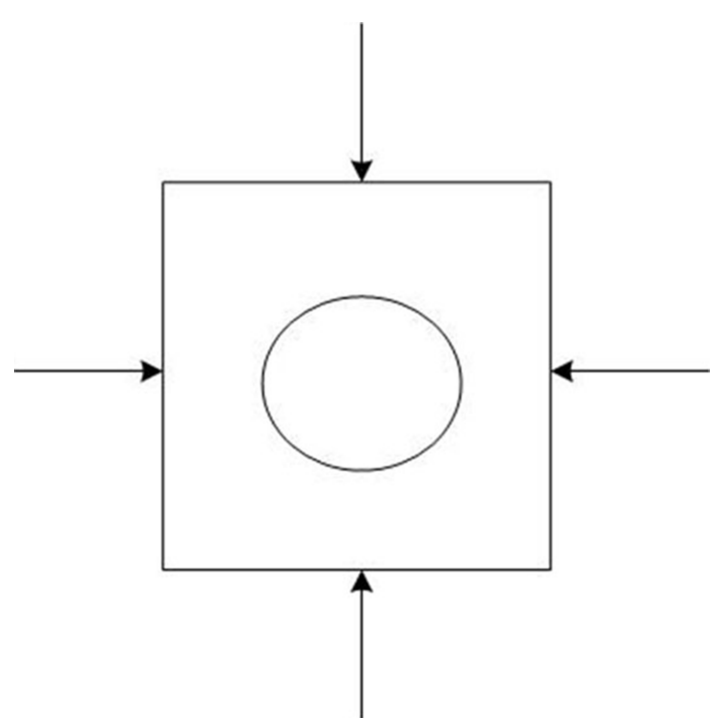

Figure 4. The road stratum model of the roadway 
Table 1. Mechanical parameters of rock strata

\begin{tabular}{lr} 
Parameter & Value \\
\hline Elastic modulus: MPa & 20000 \\
Uniaxial compressive strength: MPa & 35 \\
Internal friction angle: & \\
Ratio of uniaxial compressive strength to uniaxial & 30 \\
tensile strength & 10 \\
Residual strength: \% & $0 \cdot 1$
\end{tabular}

the square was $2 b$ and the external pressure was 1 . The pressure faced by the model could be expressed as

$$
\begin{aligned}
& \sigma_{j}=\frac{a^{2} b^{2}}{b^{2}-a^{2}} \frac{q}{\rho^{2}}+\frac{b^{2}}{a^{2}-b^{2}} q \\
& \sigma_{q}=\frac{a^{2} b^{2}}{a^{2}-b^{2}} \frac{q}{\rho^{2}}+\frac{b^{2}}{a^{2}-b^{2}} q
\end{aligned}
$$

where $\sigma_{j}$ stands for radial normal stress; $\sigma_{q}$ stands for tangential normal stress; and $\rho$ stands for density.

\section{Case study}

Taking the common circular and rectangular roadways in the mining area as an example, the failure law of rock strata in roadways was analysed using the VR system and RFPA numerical analysis system. The mechanical parameters of rock strata are shown in Table 1 .

Considering the limitation of computer performance, to reduce the computing amount, the size of the model should be as small as possible. However, in order to ensure the scientificity of the experiment, the physical parameters of the material were the same as the geometric parameters of the model. The model loading mode was also the same as that of the real experiment. Moreover, to reflect more clearly the stress distribution inside the roadway, the gravity of rock was not considered in the simulation experiment, as it cannot be realised in the actual experiment.

\section{Round roadway}

The size of the circular roadway model was $1000 \mathrm{~mm} \times 1000 \mathrm{~mm} \times$ $400 \mathrm{~mm}$, the radius of the circle was $75 \mathrm{~mm}$ and the total number of model elements was $100 \times 100 \times 40=400000$.
The failure of rock strata was simulated by RFPA, and the results are shown in Figure 5.

The red lines in the picture indicate that the strata have broken down. It was found from Figure 5 that in the initial stage (A), there were intermittent fracture zones around the roadway, which were not fully connected, and had a certain distance from the roadway. With the increase in load (B), there were gradually arcshaped fracture zones around the roadway, and cracks continued to expand and develop. The fracture zones were obvious and clear, and new fracture zones were formed in the later stage of loading (C), and the cracks which were spiral grew constantly, leading to instability of the rock stratum. The maximum axial compressive stress of the rock stratum was about $46 \cdot 27 \mathrm{MPa}$. The numerical simulation results showed that the failure of rock strata in roadways was mostly a ring-like fracture zone, and the crack development was regular.

\section{Rectangular roadway}

The side length of the rectangular roadway was $100 \mathrm{~mm}$, and other parameters were the same as those of the circular roadway. The failure of rock strata simulated by RFPA is shown in Figure 6 .

It was found from Figure 6 that the failure of rock strata in the rectangular roadway was similar to that of rock strata in the circular roadway. In the initial stage of loading (A), minor failure occurred around the roadway. With the continuation of loading (B), cracks expanded to form an independent arc-shaped crack, and, in the later stage of loading $(\mathrm{C})$, cracks expanded to a nearring crack zone. In addition, compared with the original roadway, the corner of the rectangular roadway was subjected to great compressive stress, while the four sides were subjected to greater tensile stress. The circular fracture zone was not closed, and the maximum axial compressive stress of rock stratum was about 45.64 MPa. It was found that the fracture form of the roadway rock strata might be closed or not closed.

\section{Fracture of the roadway support}

In the process of mining area excavation, in order to ensure the safety of roadways, some supporting measures are usually adopted to enhance the stability of roadways. Taking the circular roadway as an example, a supporting rock mass with $30 \mathrm{~mm}$

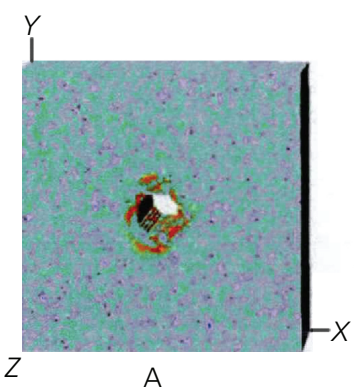

A

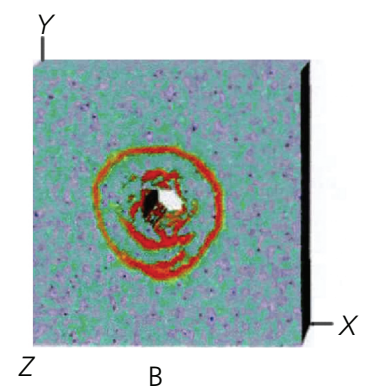

B

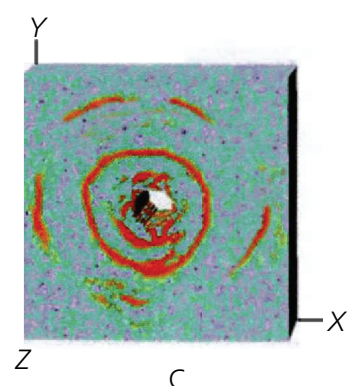

C

Figure 5. Fracture of the rock stratum of the circular roadway 

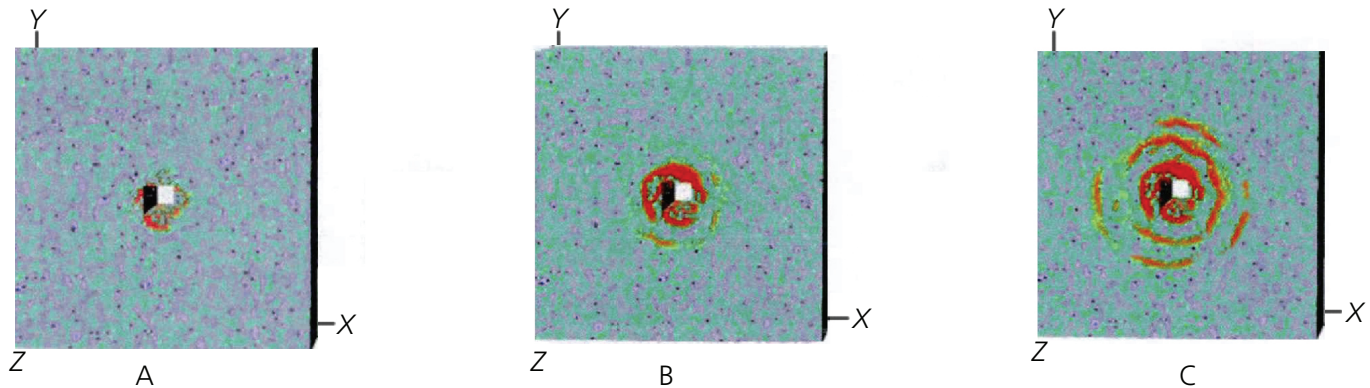

Figure 6. Fracture of rock strata in the rectangular roadway

thickness was added; the mechanical parameters of the supporting rock mass are shown in Table 2.

The fracture of rock strata simulated by RFPA is shown in Figure 7.

Figure 7 shows that the cracks in the roadway support were far away from the roadway, the roof of the roadway hardly cracked, and the fracture zone was smaller than that shown in Figure 5. However, there are many cracks in the contact part between the supporting rock mass and the natural rock mass. The supporting rock mass bore most of the tensile stress, but, because of its greater tensile strength, it would not be damaged. Moreover, the crack situation of the roadway was complex. In addition, under the action

\section{Table 2. Mechanical parameters of the supporting rock mass}

\begin{tabular}{lc} 
Parameter & Value \\
\hline Thickness: mm & 30 \\
Elastic modulus: GPa & 40 \\
Compressive strength: MPa $^{\text {Internal friction angle: }}{ }^{\circ}$ & 380 \\
Ratio of uniaxial compressive strength to uniaxial $^{\text {tensile strength }}$ & 30 \\
Residual strength: \% & 10 \\
\end{tabular}

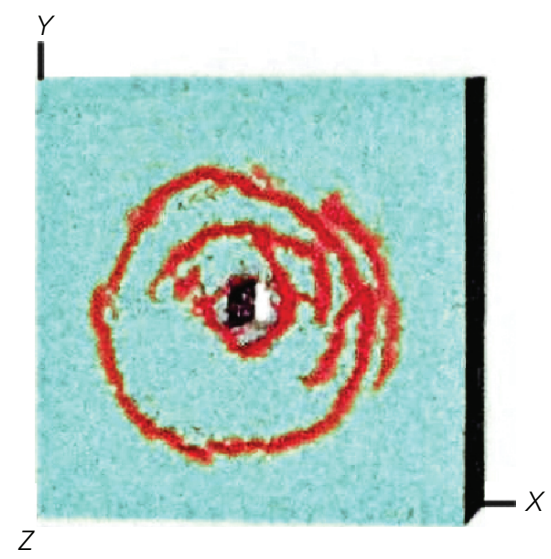

Figure 7. Fracture of rock strata of the supporting rock mass, the maximum axial compressive stress of rock stratum was about $55.67 \mathrm{MPa}$, which was obviously higher than that without the supporting mass. Thus indicating that the supporting rock mass could protect the roadway by reducing the fracture area and improve the safety of the roadway.

\section{Discussion}

Technological innovation has injected new life into traditional mineral exploitation. In the process of mineral exploitation, the disturbance of stress fields may lead to the failure and instability of rock strata, such as fracture, penetration and fracture. In the process of underground mining, the mechanical data on rock strata are complex, and it is difficult to carry out theoretical calculation and to reflect the dynamic changes of rock strata truly. Unexpected geological hazards in the process of mineral exploitation can not only seriously threaten the safety of miners, but also cause huge economic losses. Therefore, obtaining mechanism changes of rock strata and predicting geological hazards with scientific technology is of great significance to the safety and smooth progress of mining work (Li et al., 2014).

In this study, VR technology was used to study the rock stratum fracture of the roadway in a mining area of Henan Province. Roadway fracture is a common failure mechanism (Gao et al., 2015), which has important value for research. First, a VR system of the mining area was designed, a 3D model was established through the 3DMine software and then they were inputted into the VR-Platform software to form the VR system of the mining area, and then the RFPA numerical analysis system was used to analyse the mechanical data of the mining area. Taking the fracture of rock strata of the roadway as an example, the damage and pressure analysis of rock was emphatically analysed. RFPA is an analysis system based on elastic mechanism, which can calculate the stress of a model by a given displacement increment and simulate the compression, deformation and fracture of the model. First, the rock stratum fracture of circular and rectangular roadways was simulated. The simulation results showed that roadways in different shapes may have different fracture situations. In the initial stage of loading, there were relatively small cracks around the roadway. With the increase in load, cracks grew to form a long circular arc crack, which finally 
formed a near-annular fracture zone. It could be seen from the rupture of the circular roadway shown in Figure 5 that the phenomenon of zonal rupture was obvious, a multilayer ring-like rupture zone formed in the roadway and secondary cracks were fewer. It could be seen from the rupture of the rectangular roadway (Figure 6) that the change of rupture was similar to that of the circular roadway; small cracks in the initial stage of loading gradually expanded into arc-shaped cracks. It could also be found that the initial failure form of the roadway was correlated with the shape of the roadway. Unlike the circular roadway, the corner of the rectangular roadway was subjected to compressive stress and the four sides were subjected to tensile stress, resulting in tensile failure. Moreover, the circular roadway had a closed arc crack zone, while the rectangular roadway had a non-closed crack zone, which indicates that the development of cracks in the roadway was random.

Roadway support is an important problem in the mining process (Li et al., 2016). The simulation results of the roadway support suggest that increasing the support rock mass plays an important role in increasing the stability of roadways. Under the action of the supporting rock mass, the damage on the top of the roadway can be neglected. Essentially, no deformation occurs and the supporting shelter is basically complete, but there are serious fractures at the junction. In view of the important role of roadway support, it is necessary to analyse further the numerical simulation of roadway support, such as the influence of the thickness and strength of supporting rock mass on roadway fracture.

\section{Conclusion}

In this study, the application of VR technology in the mining industry was studied. After the establishment of the VR system of the mining area, mechanical data analysis was carried out using the RFPA numerical analysis system, taking the rock stratum fracture of the roadway in the mining area as an example. The simulation of the rock stratum fracture of circular and rectangular roadways revealed some laws of rock stratum fracture. Then, the role of the roadway support was analysed, and it was found that the support could improve the safety of roadways. This study proves the application value of VR technology in the mining industry and provides some bases for its further application in the mining industry.

\section{REFERENCES}

An W and Cai Z (2010) Study on the three-dimensional geometric modeling of the virtual roadway in mine. Microcomputer Information 26(22): 223-225, https://doi.org/10.3724/SP.J.1187.2010.00953.

Bastug E, Bennis M, Medard M and Debbah M (2017) Toward interconnected virtual reality: opportunities, challenges, and enablers. IEEE Communications Magazine 55(6): 110-117, https://doi.org/10. 1109/MCOM.2017.1601089.

Bellanca JL, Orr TJ, Helfrich W et al. (2017) Assessing hazard identification in surface stone mines in a virtual environment. In Advances in Applied Digital Human Modeling and Simulation (Duffy VG (ed.)). Springer, Cham, Switzerland, pp. 217-230.

Gao F, Stead D and Kang H (2015) Numerical simulation of squeezing failure in a coal mine roadway due to mining-induced stresses. Rock
Mechanics and Rock Engineering 48(4): 1635-1645, https://doi.org/ 10.1007/s00603-014-0653-2.

Li HM and Kang BS (2014) A virtual reality safety training system for coal mining industry. Applied Mechanics and Materials 687-691: 2371-2374, https://doi.org/10.4028/www.scientific.net/AMM.687-691.2371.

Li Y, Yang T, Liu H et al. (2014) Construction and safety monitoring analysis of 3D visualization system for Da'anshan coal mine. Journal of Mining and Safety Engineering 31(2): 277-283.

Li Q, Shi W and Yang R (2016) Deformation mechanisms in a coal mine roadway in extremely swelling soft rock. SpringerPlus $\mathbf{5 ( 1 )}$ : article 1310, https://doi.org/10.1186/s40064-016-2942-6.

Merchant Z, Goetz ET, Cifuentes L, Keeney-Kennicutt W and Davis TJ (2014) Effectiveness of virtual reality-based instruction on students' learning outcomes in K-12 and higher education: a meta-analysis. Computers \& Education 70(1): 29-40, https://doi.org/10.1016/j. compedu.2013.07.033.

Qi AL, Wang H, Wu HY and Ma HW (2015) Research on the collision detection technology of coal-cutting machinery in remote virtual control. Applied Mechanics and Materials 738-739: 863-866, https:// doi.org/10.4028/www.scientific.net/amm.738-739.863.

Rizzo A, Hartholt A, Grimani M, Leeds A and Liewer M (2014) Virtual reality exposure therapy for combat-related posttraumatic stress disorder. Computer 47(7): 31-37, https://doi.org/10.1109/MC.2014.199.

Stothard P, Squelch A, Stone R et al. (2015) Taxonomy of interactive computer-based visualisation systems and content for the mining industry - part 2. Mining Technology 124(2): 83-96, https://doi.org/10. 1179/1743286315Y.0000000006.

Wei YQ, Xiao J and Hao DQ (2014) Virtual campus roaming system optimization algorithms based on virtual reality. Advanced Materials Research 834-836: 1903-1906, https://doi.org/10.4028/www. scientific.net/AMR.834-836.1903.

Wen CR, Liu H, Wang ZW, Fan YQ and Zhao PX (2014) Analysis on the application of virtual reality technology to the development of CBT in aviation industry. Applied Mechanics and Materials 687-691: 2917-2920, https://doi.org/10.4028/www.scientific.net/AMM.687-691. 2917.

Wu D, Hu Y and Fan X (2009) Visual simulation for granular rocks crush in virtual environment based on fractal geometry. Simulation Modelling Practice and Theory 17(7): 1254-1266, https://doi.org/10. 1016/j.simpat.2009.04.010.

Xie J, Yang Z, Wang X et al. (2018) A virtual reality collaborative planning simulator and its method for three machines in a fully mechanized coal mining face. Arabian Journal for Science and Engineering 43(9): 4835-4854, https://doi.org/10.1007/s13369-018-3164-8.

Zhang H (2017) Head-mounted display-based intuitive virtual reality training system for the mining industry. International Journal of Mining Science and Technology 27(4): 717-722, https://doi.org/10. 1016/j.ijmst.2017.05.005.

\section{How can you contribute?}

To discuss this paper, please submit up to 500 words to the editor at journals@ice.org.uk. Your contribution will be forwarded to the author(s) for a reply and, if considered appropriate by the editorial board, it will be published as a discussion in a future issue of the journal. 